\title{
Use of blast furnace slag and water treatment residues to reduce the runoff of dissolved reactive phosphorus from agricultural lands
}

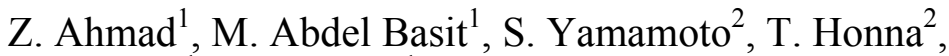 \\ H. Yasuda ${ }^{1}$ \& M. Inoue ${ }^{1}$ \\ ${ }^{1}$ Arid Land Research Centre, Tottori University, Japan \\ ${ }^{2}$ Faculty of Agriculture, Tottori University, Japan
}

\begin{abstract}
Continuous use of phosphorus (P) fertilizers has created severe environmental concerns. Control of non-point source of $\mathrm{P}$ contamination is the biggest challenge. In current study, residues from the water treatment facilities (WTR) and blast furnace slag (BFS) were tested for their ability to reduce the P runoff. Residues from water treatment facilities have been extensively tested under crop or grass cover but less is know when applied to bare lands. Similarly, BFS has been studied for its use as a filtering material in wastewater treatment plants, but its use on agricultural lands for P control has not been reported yet. A silty clay loam soil was amended with BFS and WTR at the rate of $50 \mathrm{~g} \mathrm{~kg}^{-1}$ soil. Chemical P was applied at the rate of $400 \mathrm{~kg} \mathrm{ha}^{-1}$. Bared soil surface with two roughnesses (low and high) was exposed to two artificial rainfall intensities (35 and $75 \mathrm{~mm} \mathrm{~h}^{-1}$ ). Each treatment was exposed to three rainfall events with a constant rainfall depth of $70 \mathrm{~mm}$. Results of the study showed that, regardless of rainfall intensity and soil roughness, dissolved reactive P (DRP) reduced over the runoff time from both amended pots while from control pots an increasing trend was observed. Water treatment residues reduced the mean DRP concentration by $27.3 \%$ and DRP load by $32 \%$ as compared to un-amended plots. Though the trend was declining but $\mathrm{P}$ concentrations were higher from BFS amended plots compared to control. DRP concentrations were lower under high rainfall intensity than low rain intensity due to the dilution factor. This study affirms the ability of WTR to reduce the P mobility from bare soils as well however further studies are needed to test the effectiveness of BFS under filed conditions.

Keywords: dissolved reactive phosphorus, simulated rainfall intensity, soil roughness, blast furnace slag, water treatment residues.
\end{abstract}




\section{Introduction}

Agriculture is the primary source of non-point source of Phosphorus (P) pollution which is degrading the streams and lakes quality. To reduce this $\mathrm{P}$ transport to surface water bodies, many strategies and management practices have been investigated. Some management practices include conservation tillage, crop residue management, cover crops, buffer strips, contour tillage, runoff water impoundment, and stopping land application of biosolids once the threshold soil test $\mathrm{P}$ value is reached. But $\mathrm{P}$ based compost application or stopping $\mathrm{P}$ application will not serve the goals [1] because there are still many highly $\mathrm{P}$ contaminated soils which are posing threats to the environment. Analogously, to reduce the dissolved $\mathrm{P}$ in runoff water or to increase the $\mathrm{P}$ holding capacity of soil, a number of soil amendments have also been attempted. As $\mathrm{P}$ is fixed by oxides of iron, aluminium and calcium carbonates present in soil, any material which has high contents of these elements will ultimately increase the soil $\mathrm{P}$ holding capacity.

Blast furnace slag (BFS) is one of the materials which have been used for $\mathrm{P}$ removal in wastewater-treatment systems [2]. Blast furnace slag is a non-metallic co-product which is produced in iron industries. It consists primarily of silicates, alumino-silicates, and calcium-alumina-silicates. Because of the high $\mathrm{Al}$ and $\mathrm{Ca}$ contents this material has been extensively studied for its ability to fix the P. These investigations showed that the material has strong potential for P-removal [3]. However, use of BFS on agricultural lands to reduce the P mobility has not been investigated yet. Similarly, drinking water treatment residuals (WTR) are effective due to their high $\mathrm{P}$ sorbing capacity. Drinking water treatment residuals are often rich in amorphous $\mathrm{Fe}$ or $\mathrm{Al}$ oxides due to the use of $\mathrm{Fe}$ or Al salts as coagulants during drinking water treatment. Several field and lab studies have been conducted to evaluate the use of WTR as a P sorbent and reported that WTR significantly reduces the P losses. Water treatment residues are applied on the surface, incorporated into soil, or co-blended with different $\mathrm{P}$ sources. However, performance of WTR under different soil roughness conditions has not been fully explored. Therefore, the current study was designed to evaluate i) the potential use of BFS on arable lands to reduce DRP concentration through runoff, ii) the effect of soil roughness on the performance of WTR, and iii) interaction of soil roughness conditions and rainfall intensities under different soil amendments.

\section{Materials and methods}

\subsection{Rainfall simulator}

An indoor dripper-type rainfall simulator installed at the Arid Land Research Center, Tottori University, Japan was used in this study. Rain simulation was done from a height of $12 \mathrm{~m}$. The experimental area $\left(2.3 \mathrm{~m}^{2}\right)$ was equipped with an adjustable-angle steel plate to adjust the slope angle of the plots and was 
protected against the air currents by plastic sheets. The deck was adjusted to a slope of $8 \%$.

\subsection{Soil and soil amendments used}

A silty clay loam soil (Fulvudand) was used in this study. The soil was air dried, then crushed mechanically and sieved using a $2 \mathrm{~mm}$ mesh sieve. Water treatment sludge was collected from the Kyo-ritsu water purification plant, Hiroshima, Japan. Ground granulated blast furnace slag (BFS) was collected from Aichi Steel Corporation, Aichi, Japan. Water treatment sludge was in the form of granules $(<5 \mathrm{~mm})$ which were crushed to powder $(<0.5 \mathrm{~mm})$.

A steel pan of $1.0 \times 0.5 \times 0.16 \mathrm{~m}$ with four drain holes, and side and back walls $0.03 \mathrm{~m}$ higher than the soil surface, was used to prepare the soil plots. First of all, each pan was filled with a gravel filter of $0.04 \mathrm{~m}$ depth to facilitate the lateral flow of the water without causing water logging in the pan. Before packing, the top $5 \mathrm{~cm}$ of soil was amended with BFS or WTR at the rate of $5 \mathrm{~g}$ per $100 \mathrm{~g}$ of soil. The same soil was mixed with chemical P fertilizer in the form of $\mathrm{KH}_{2} \mathrm{PO}_{4}$ at the rate of $400 \mathrm{~kg} \mathrm{P} \mathrm{ha}{ }^{-1}$. The packing was done by hand in a systematic way using a wooden plank and care was taken to make all the plots as homogeneous and uniform as possible.

\subsection{Overland flow and runoff sampling}

Levelled and firm soil surface of each treatment was then changed to low or high rough using two hand spades. To achieve the low soil roughness a spade with a $2 \mathrm{~cm}$ long blade was used, while to achieve high soil roughness a spade with blade of $5 \mathrm{~cm}$ length was used. Two rainfall intensities 30 and $65 \mathrm{~mm} \mathrm{~h}^{-1}$ were used for each treatment with the rainfall depth of about $60 \mathrm{~mm}$ for each run. Each treatment was subjected to three consecutive runs. The first run was carried out on a dry surface (dry run) while the other two runs were done over the wet surface (wet run). Each subsequent run was carried out within the time period of $12 \mathrm{~h}$. Three soil amendments, two soil roughness levels, two rainfall intensities and two replications with three runs gave a total of 72 runs.

Runoff water was collected over the time and allowed to settle for $1 \mathrm{~h}$, and then a subsample was filtered through a $0.45 \mu \mathrm{m}$ cellulose acetate membrane filter for DRP, Al, Fe, and K analysis. Quantification of DRP, Al, Fe and K was done on ICP-AES with in $24 \mathrm{~h}$ of collection. Data collected during the study were statistically analyzed using StatView software.

\section{Results}

\subsection{Effect of low rainfall intensity $\left(30 \mathrm{~mm} \mathrm{~h}^{-1}\right)$}

Overall mean DRP concentration was higher under low rainfall intensity as compared to high rainfall intensity. Changes in DRP concentration with the passage of runoff time were observed and results are shown in Figs. 1 to 4 . During the runoff event, irrespective of soil roughness, DRP concentration in un- 
amended (control) plots was lower at the start of the first run (Figs. 1 and 2) and increased with the increase in time of runoff over the surface. Dissolved reactive $\mathrm{P}$ concentration continued to increase during the second run from un-amended plots with low soil roughness (LSR) (Fig. 1). However, at the start of the third run, DRP concentration was lower in runoff water as compared to the first and second runs, and increase was less with the time of runoff (Fig. 1). Contrary to un-amended plots, DRP concentration started to decrease with the time of runoff over the plots amended with water treatment residues (WTR) and blast furnace slag (BFS) (Fig. 1).
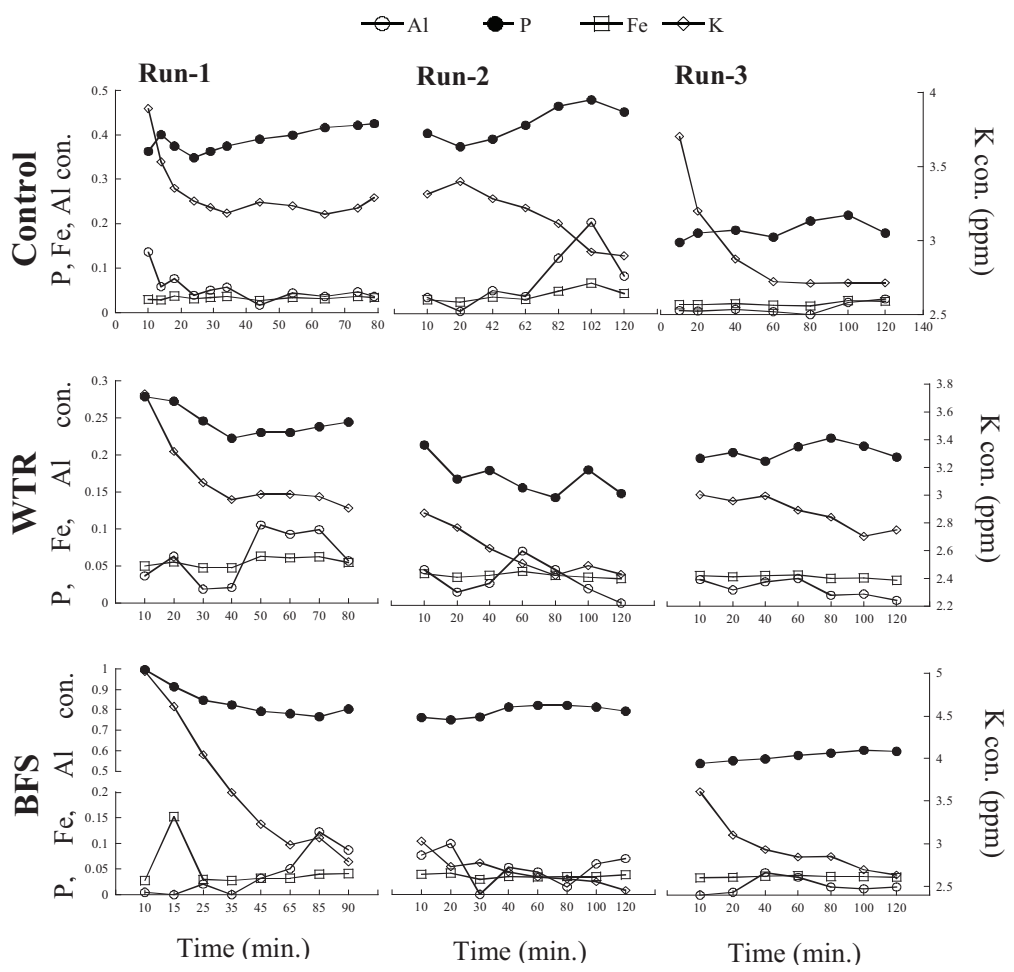

Figure 1: $\quad$ Effect of low rainfall intensity $\left(30 \mathrm{~mm} \mathrm{~h}^{-1}\right)$ and low soil roughness on nutrients concentration in runoff water.

Change in soil roughness from low to high did not change the overall trend of DRP concentration in runoff water under $30 \mathrm{~mm} \mathrm{~h}^{-1}$ rainfall intensity (Fig. 2). Among the two soil roughness conditions, it was observed that DRP concentration in runoff water was considerably less under the high soil roughness as compared to the low roughness condition. The difference of soil roughness on DRP under low rainfall intensity is more obvious in the control and WTR amended plots (Figs. 1 and 2). 


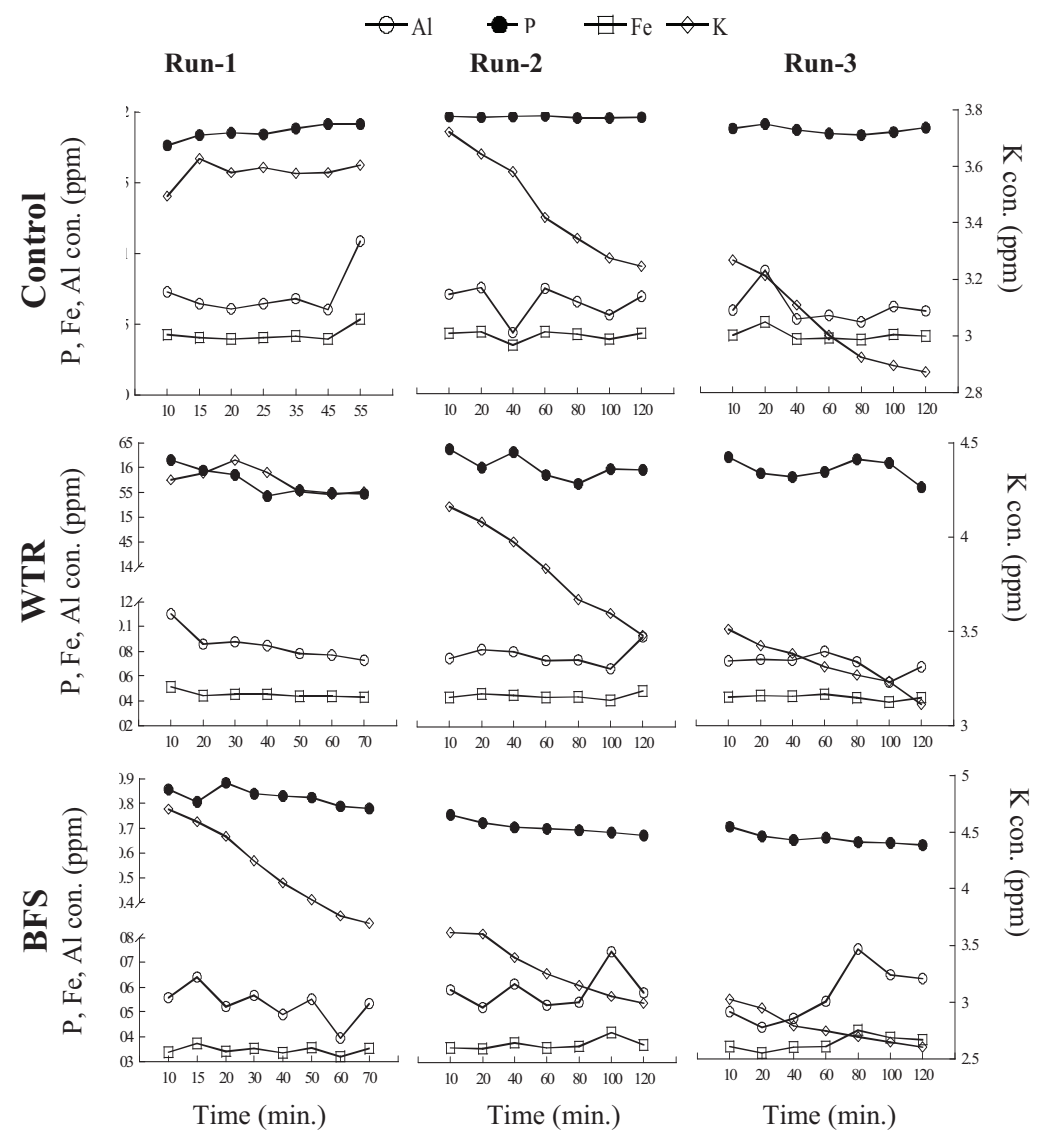

Figure 2: $\quad$ Effect of low rainfall intensity $\left(30 \mathrm{~mm} \mathrm{~h}^{-1}\right)$ and high soil roughness on nutrients concentration in runoff water.

\subsection{High rainfall intensity $\left(65 \mathrm{~mm} \mathrm{~h}^{-1}\right)$}

Similar to low rainfall intensity, the trend of DRP in runoff from amended plots did not change significantly with the increase in rainfall intensity under both soil roughness levels. Under the low soil roughness, DRP concentration in control treatment increased with the time of runoff (Fig. 3). A similar trend was observed during the second run and maximum DRP concentrations were recorded during the third run. In WTR amended plots, DRP concentration decreased over the time of runoff during the first run (Fig. 3). In the second run, DRP concentrations were higher at the start of the run, but later trend was linear, while in the third run DRP concentration in runoff water was relatively steady (Fig. 3). Similarly, in BFS amended plots, DRP concentration decreased with time of runoff in all three runs and minimum DRP concentrations were recorded in the third run (Fig. 3). 


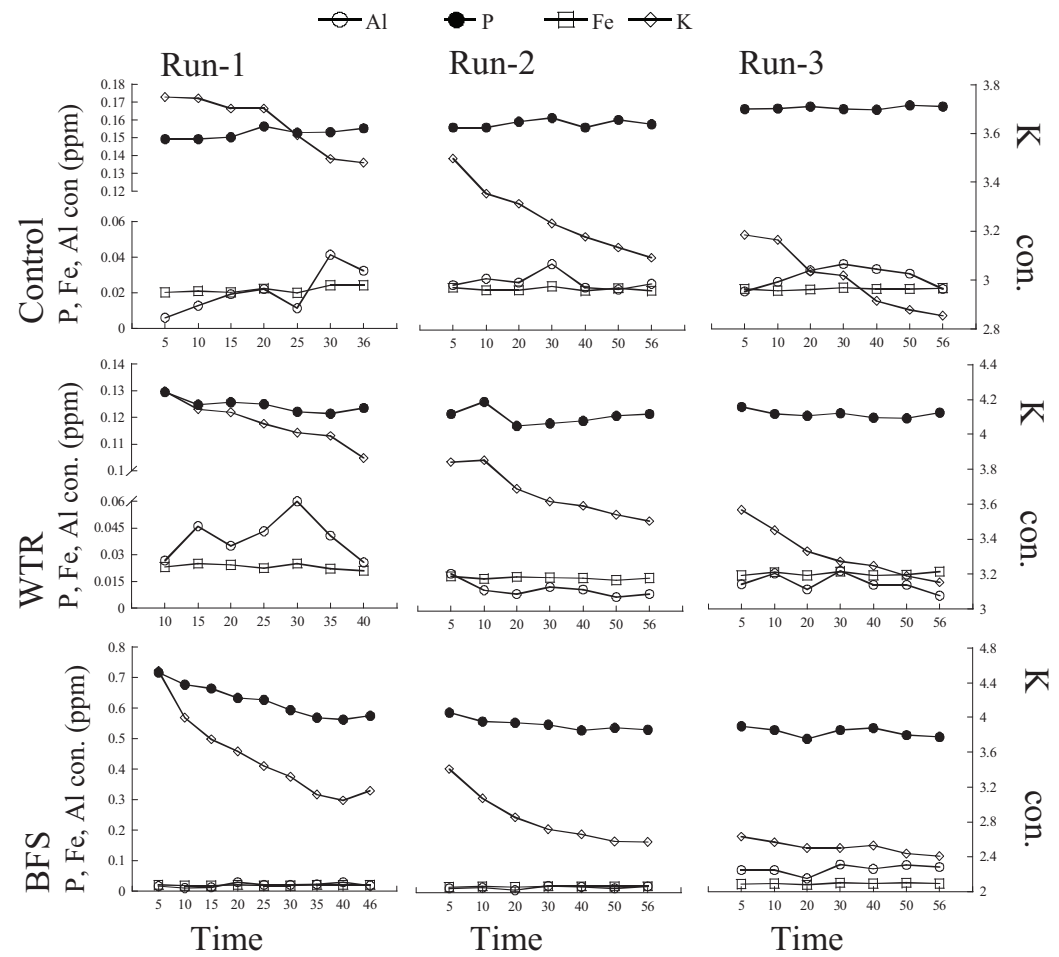

Figure 3: Effect of high rainfall intensity (65 $\mathrm{mm} \mathrm{h}-1)$ and low soil roughness on nutrients concentration in runoff water.

Under high soil roughness, DRP concentration remained stable with the runoff time in the control plots (Fig. 4). During the second run, DRP concentration increased until $30 \mathrm{~min}$ of runoff and then became stable (Fig. 4). In the third run, DRP concentration from the control plots remained steady until the first 20 min of runoff, and then it slightly decreased to a steady level (Fig. 4).

Plots amended with WTR showed decrease in DRP concentration during the first run (Fig. 4), while in the second run DRP concentration remained relatively stable. Concentration of DRP in runoff remained steady during the third run, but a slight decrease was observed toward the end. In the BFS amended plots, decrease in DRP concentration was sharp in the first run (Fig. 4), but in the second run DRP concentration remained steady (Fig. 4). During the third run, DRP concentration was also steady but slightly declined toward the end of runoff. 


\subsection{Iron, aluminium and potassium concentration in runoff}

Changes in $\mathrm{Fe}, \mathrm{Al}$ and $\mathrm{K}$ concentrations are also shown in Figures 1 to 4. It was observed that the overall mean $\mathrm{Al}$ concentration in runoff water was higher under low rainfall intensity. Increasing the soil roughness from low to high also increased the $\mathrm{Al}$ concentration in runoff. Among the amendments, $\mathrm{Al}$ concentration did not change greatly. However, Al concentrations were slightly higher from WTR under HSR. A trend similar to Al was observed for $\mathrm{Fe}$ concentration under both rainfall intensities and soil roughness. No variation in $\mathrm{Fe}$ concentration was observed from any of the three soil amendments. While K concentration in runoff water did not change with any change in rainfall intensity or soil amendment, however, $\mathrm{K}$ concentration was slightly higher under high soil roughness conditions.

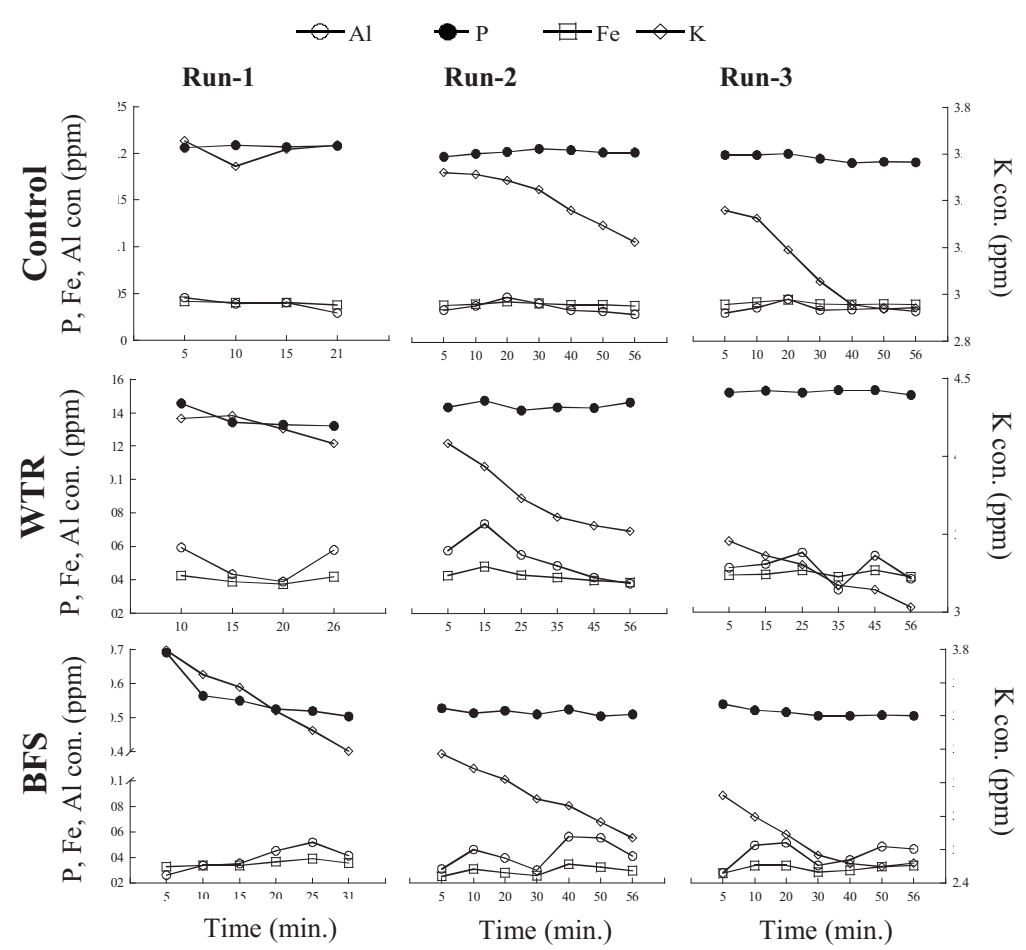

Figure 4: Effect of high rainfall intensity $(65 \mathrm{~mm} \mathrm{~h}-1)$ and high soil roughness on nutrients concentration in runoff water.

\section{Discussion}

It was observed that, under both soil roughness levels, overall DRP concentrations decreased with the increase in rainfall intensity from $30 \mathrm{~mm} \mathrm{~h}^{-1}$ to 
$65 \mathrm{~mm} \mathrm{~h}^{-1}$. Reduced DRP concentration under high rainfall might be due to the dilution factor as a high volume of runoff water flows over a short period of time. Previous studies examining nutrient concentrations in runoff related to rainfall intensity have also hinted at dilution as a key process affecting $\mathrm{N}$ and $\mathrm{P}$ concentrations in runoff [4]. Slight increase of DRP concentration in control treatment might be due to the different physico-chemical and hydraulic processes. In the first dry run, soil was dry and $\mathrm{P}$ was also applied in dry form, so with the onset of rain event dissolution of $\mathrm{P}$ occurred, which is highly water soluble, so DRP concentration started to increase over time. Smith et al. [5] compared different $\mathrm{P}$ fertilizers and suggested that the fertilizer granules released $\mathrm{P}$ to the water during the wetting process. Among the two soil amendments, WTR appeared to be very effective in reducing DRP runoff from the bare soil. Mean DRP concentration in runoff water was reduced by $27.3 \%$ and DRP load by $32 \%$ from the WTR amended plots as compared to the control treatment. Incorporation or surface application of WTR has been reported to reduce dissolved and extractable $\mathrm{P}$ in soil by several researchers $[6,7]$. In BFS amended plots, the trend of DRP concentration in runoff was similar to the WTR. However, the overall DRP concentrations in all BFS amended plots were higher than the WTR and control treatment. Blast furnace slag has been extensively explored as substrates for P removal from constructed wetland systems, both in the laboratory and field [8]. Phosphorus adsorption capacity of BFS varied among the different studies, which is expected due to the variation in experimental setup, material used and different P loads studied. However, we could not find any study showing the efficiency of BFS in soils to compare our results.

Overall $\mathrm{Al}$ and $\mathrm{Fe}$ concentrations did not vary significantly under any soil amendment and were in the limits of USEPA drinking water standards [9]. Slightly higher Al concentrations from WTR amended plots was anticipated due to the higher Al contents of WTR as well as high indigenous soil Al contents. It was observed that $\mathrm{K}$ concentrations were higher in runoff as compared to other nutrients observed, which might be due to the higher soil native $\mathrm{K}$ contents as well as $\mathrm{K}$ added in the form of $\mathrm{KH}_{2} \mathrm{PO}_{4}$ with $\mathrm{P}$ dose. Munodawafa [10] stated that amount of nutrient loss is also depends on the fertility status of the soil and the abundance of a particular nutrient in the soil.

\section{Acknowledgement}

The authors are thankful to Japan Society for the Promotion of Science (JSPS) for providing the grant to conduct this study.

\section{References}

[1] Zahoor, A., Honna, T. \& Yamamoto, S., Leachability and phytoavailability of NPK from different bio-composts under chloride and sulphate dominated irrigation water. Journal of Environmental Quality, 37(3), pp. 1288-98, 2008. 
[2] Korkusuz, E.A., Beklioğlu, M. \& Demirer, G.N., Use of blast furnace granulated slag as a substrate in vertical flow reed beds: Field application. Bioresource Technology, 98, pp. 2089-2101, 2007.

[3] Sakadevan, K. \& Bavor, H.J., Phosphate adsorption characteristics of soils, slags and zeolite to be used as substrates in constructed wetland systems. Water Research, 32, 393-399, 1998.

[4] Fraser, A.I., Harrod, T.R. \& Haygarth, P.M., The effect of rainfall intensity on soil erosion and particulate phosphorus transfer from arable soils. Water Science and Technology, 39, pp. 41-45, 1999.

[5] Smith, D.R., Owens, P.R., Leytem, A.B. \& Warnemuende, E.A., Nutrient losses from manure and fertilizer applications as impacted by time to first runoff event. Environmental Pollution, 147, pp. 131-137, 2007.

[6] Oladeji, O.O., O’Connor, G.A. \& Brinton, S.R., Surface applied water treatment residuals affect bioavailable phosphorus losses in Florida sands. Journal of Environmental Management, 88, pp. 1593-1600, 2008.

[7] Elliott, H.A., O’Connor, G.A., Lu, P. \& Brinton, S., Influence of water treatment residuals on phosphorus solubility and leaching. Journal of Environmental Quality, 31, pp. 1362-1369, 2002.

[8] Westholm, L.J., Substrates for phosphorus removal-Potential benefits for on-site wastewater treatment? Water Research, 40, pp. 23-36, 2006.

[9] EPA (Environmental Protection Agency), 2006 Edition of the drinking water standards and health advisories. EPA 822-R-06-013. Washington, DC. www.epa.gov/waterscience/criteria/drinking/dwstandards.pdf

[10] Munodawafa, A., Assessing nutrient losses with soil erosion under different tillage systems and their implications on water quality. Physics and Chemistry of Earth, 32, pp. 1135-1140, 2007. 